\title{
Comparison of theoretical effects of encapsulation floxuridine anticancer drug with boron nitride nanotube and carbon nanotube with NBO and QTAIM studies
}

\author{
Sahar Ghahremani ${ }^{1}$, Marjaneh Samadizadeh ${ }^{2}$, Mehrnoosh Khaleghian ${ }^{3}$ \\ ${ }^{I}$ PhD student in Organic Chemistry, Department of Chemistry, Central Tehran Branch, Islamic Azad University, \\ Tehran, Iran \\ ${ }^{2}$ PhD in Organic Chemistry, Department of Chemistry, Central Tehran Branch, Islamic Azad University, Tehran, Iran \\ ${ }^{3 P h D}$ in Physical Chemistry, Department of Chemistry, Islamshahr Branch, Islamic Azad University, Islamshahr, Iran
}

\begin{abstract}
Background: The purpose of using nano-carriers for drugs delivery, such as nanotubes, is slow release of drug and reducing side effects of drugs. Drugs are very active due to their many functional groups. Therefore, reactivity of drug is reduced by being in nanotube field due to electronic resonance of drug with nanotube and it stays longer in body. As a result, less amount of drug is used and fewer side effects occur.

Materials and methods: In present study, boron nitride nanotubes $(n=9, m=9)$ with 7 angstroms length and carbon nanotubes $(n=9, m=9)$ with 7 angstroms were used to compare effects of encapsulating anticancer drug Floxuridine with this nanotube. Using density functional theory (DFT) at theoretical level of B3LYP / 6-31G *, structure of drug and BNNT $(9,9-7)$, CNT $(9,9-7)$ and nano- drug systems were optimized.

Results: Using optimized structures, spatial parameters such as bond length and bond angels, HOMOLUMO orbitals, graphs of density of states (DOS), natural bond orbital (NBO), electronic properties, parameters of atoms in molecules (AIM) and molecular electrostatic potential (MEP) were discussed.

Conclusion: Analysis of adsorption energy and thermodynamic functions shows that the process of encapsulation of the drug by both nanotubes is favorable and based on the results of NBO and AIM, BNNT nanotubes are more suitable for encapsulation of fluoxoridine.

Keywords: Boron nitride nanotube, Carbon nanotube, Anticancer drug, Density functional theory (DFT), Natural bond orbital (NBO), Parameters of atoms in molecules (AIM).

Cited as: Ghahremani S, Samadizadeh M, Khaleghian M. Comparison of theoretical effects of encapsulation floxuridine anticancer drug with boron nitride nanotube and carbon nanotube with NBO and QTAIM studies. Medical Science Journal of Islamic Azad University, Tehran Medical Branch 2020; 30(4): 363-375.
\end{abstract}

Correspondence to: Mehrnoosh Khaleghian

Tel: +989123109682

E-mail: mehr_khaleghian@yahoo.com

ORCID ID: 0000-0002-8218-5779

Received: 9 Dec 2019; Accepted: 15 Feb 2020 
مجله علوم يزشكى دانشكاه آزاد اسلامى

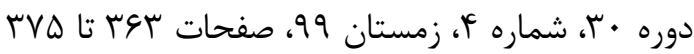

Original

Article

\title{
مقايسه تئورى اثرات كيسوله كردن داروى ضد سرطان فلوكسوريدين توسط نانولوله نيتريد بور و نانولوله كربن با مطالعات NBO و QTAIM
}

\author{
سحر قهرمانى'، مرجانه صمدى زاده ‘، مهرنوش خالقيان \\ 'انشجوى دكتراى شيمى آلى، كروه شيمى، واحد تهران مركزى، دانشَاه آزاد /سلامى، تهران، /يران

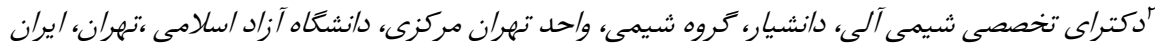

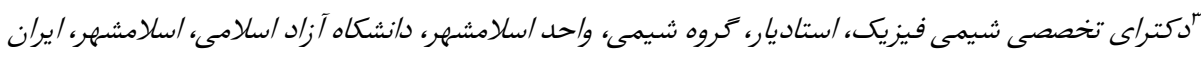

جـكنه

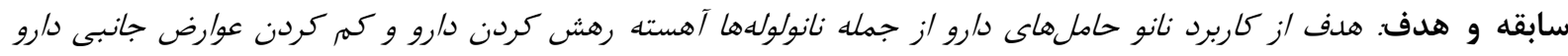

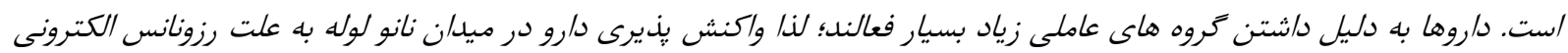

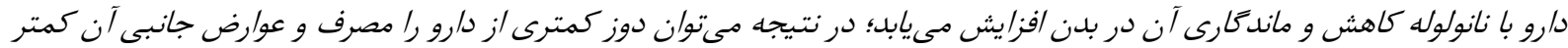

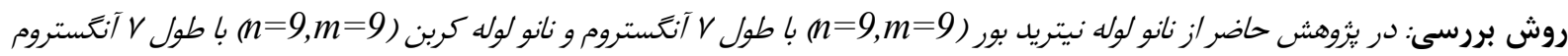

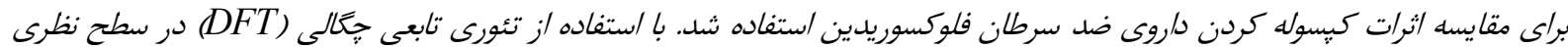

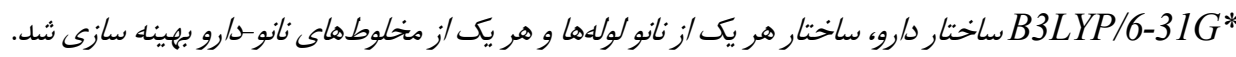
يافتهها: با /ستفاده /ز ساختارهاى بهينه بارامترهاى فضايى مانند طول بييوند و زاويئ بيوند، اوربيتال هاى

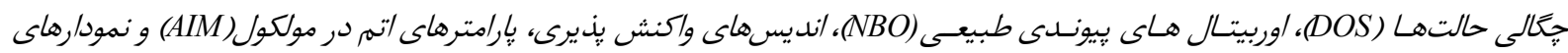

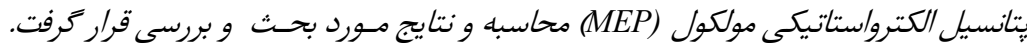
نتيجه كيرى: تجزيه و تحليل انرزى جذب و توابع ترموديناميكى نشان مى دهد فرايند كبسوله كردن دارو توسط هر دو نانو لوله مطلوب است و براساس نتايج حاصل /ز NBO و AIM، نانو لوله BNNT براي كبيسوله كردن داروى فلوكسوريدين مناسب تر /ست.

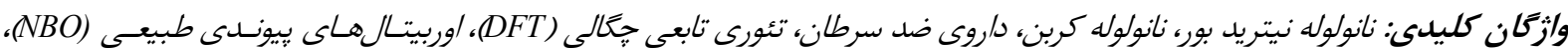

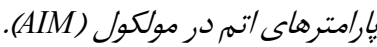

سرطان كبد و سرطان روده ى بزرگ است (1، ؟). اما جالشى كـهـ مقدمه وجود دارد اين است كه عوامل شيمى درمـانى سـرطان cytotoxic هستند و به ندرت سلولهاى سرطانى را از سلولهاى طبيعى جدا

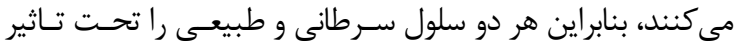

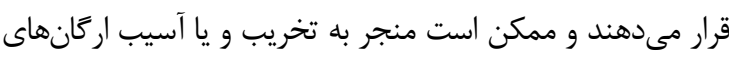

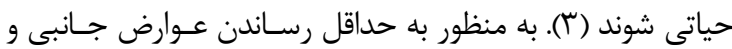
سميت داروها يك روش موثر، ارسال داروهاى شيميايى بــه نقـاط

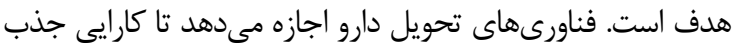

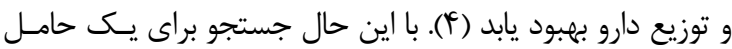

$$
\begin{aligned}
& \text { داروهاى شيمى درمانى براى درمان سرطان بسـيار مهـم هسـتند. }
\end{aligned}
$$

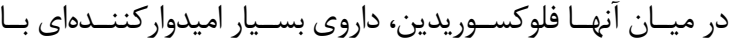

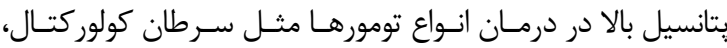

آدرس نويسنده مسئول: اسلامشهر، كروه شيمى، واحد اسلامشهر، دانشكاه آزاد اسلامى، مهرنوش خالقيـان (email: mehr_khaleghian@yahoo.com ORCID ID: 0000-0002-8218-5779

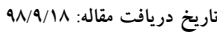

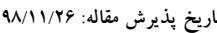


ضدسرطان فلوكسوريدين جهت ارتقاء سيستم هاى انتقال دارو بـه سلولهاى بيمار با افزايش پايدارى دارو و كـاهش بــرهمكنش دارو

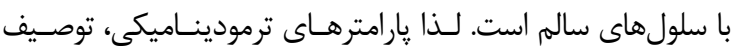

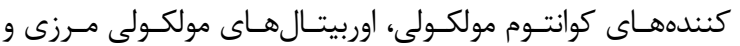
اوربيتال طبيعى بيوند (NBO)، نظريه كوانتـومى اتـم در مولكـول

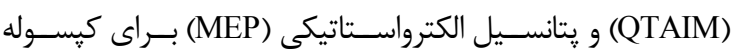
كردن داروى ضد سـرطان فلوكسـوريدين توسـط BNNT و CNT بررسى و مقايسه مىشود.

\section{مواد و روشها}

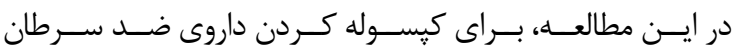

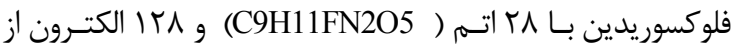

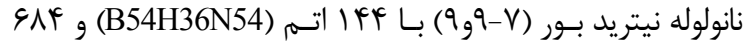

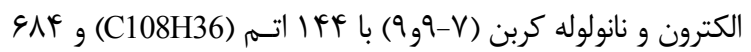

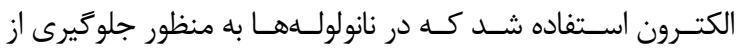
يیجش و مسدود شدن نانولوله از نظر ساختارى، كاهش و سادگى

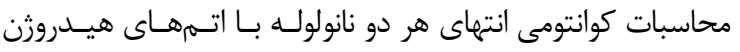

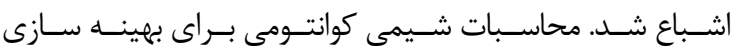

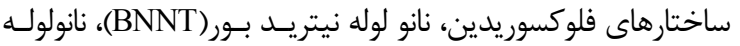

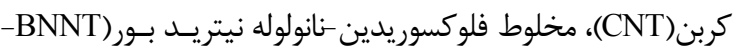
(Floxuridine

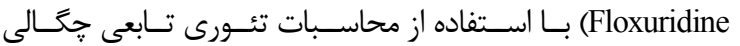
(DFT) در سطح تئورى B3LYP/6-31G و با استفاده از نرم افـزار

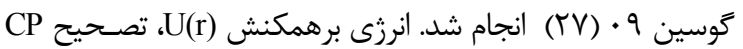

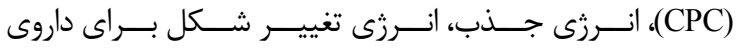

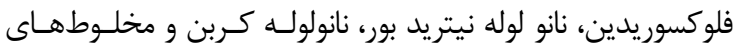

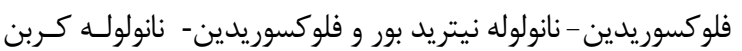
به ترتيب با استفاده از روابط زير به دست مى آيد: $U(r)=E_{\mathrm{MN}}-E_{\mathrm{M}}-E_{N}+\Delta C P=E_{\mathrm{MN}}-E_{\mathrm{M} / \Delta Q}-$ $E_{N / a Q}$

(1)

$$
\begin{aligned}
& \Delta C P=\left(E_{\mathrm{M}}-E_{M / a Q}\right)+\left(E_{N}-E_{N / 5 Q}\right) \\
& E_{\text {ais }}=E_{M N}-E_{M}-E_{N} \\
& E_{D e f M}=\left(E_{M}-E_{M / B Q}\right) \\
& E_{D e f N}=\left(E_{N}-E_{N / B Q}\right)
\end{aligned}
$$

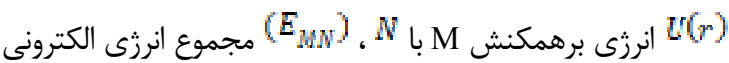

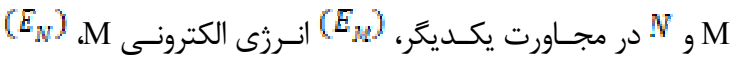
انـرزى الكترونـى N ،
دارو جالش برانكَيز است، زيــرا وسـايل حمـل و نقـل كـه در بـدن انسان استفاده مىشوند بايد غير سمى و زيست سازگار باشند (ه). كنجاندن داروهاى شيمى درمانى داخل حفرههاى قابـل دسـترس

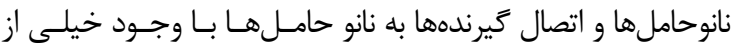
مشكلات روش بسيار اميدواركننده اى براى هدف قرار دادن دقيق

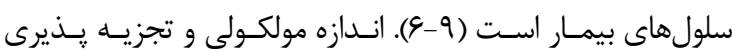

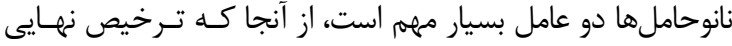

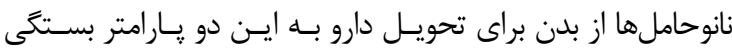

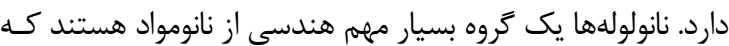
در بيوتكنولوزى و يزشـكى مـورد اسـتفاده قـرار مسى گيرنـد ( •(1).

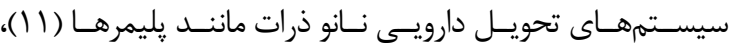

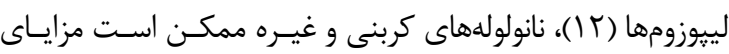
متعددى نسبت به فرم هاى دارويسى معمـولى داشـته باشــند كـهـ

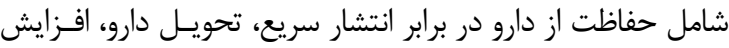

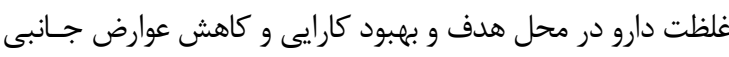
نامطلوب است (T). به طور خاص به نانولولههاى كربنسى (CNTs) به دليـل خــواص فيزيكـى و شــيميايى و بيولـوزيكى منحصـر بــهـ

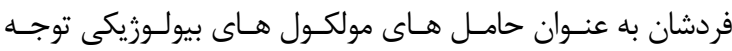
فراوانى كردهاند (9، F (1، ه 1). نانولولههاى نيتريد بور از ميان تمـام

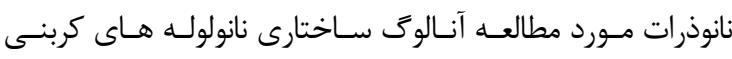

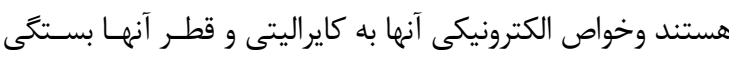

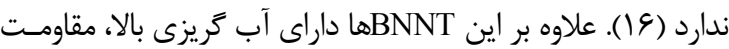

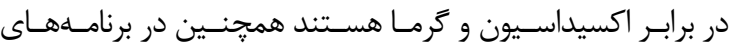

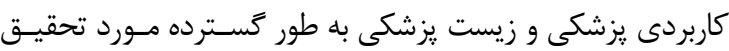

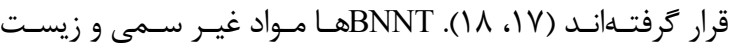

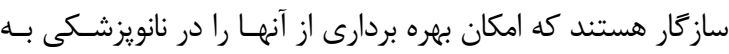

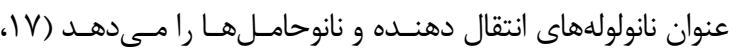

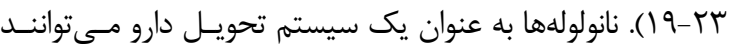
داروها را از تخريب محافظت كنند (YF). مطالعات متعـدد DFT و

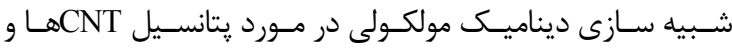
BNNT

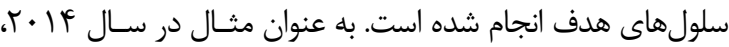
Mejri

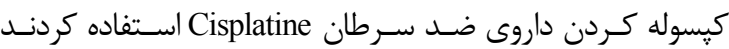
(TD) و يا در مطالعه مشابهى كه توسـط El Khalifi و همكـارانش

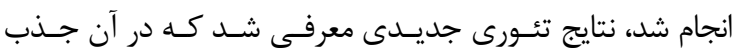

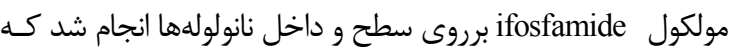
مولكول مى تواند به طور خود به خود درون نانولوله داخـل ديـواره-

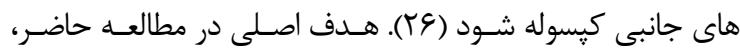

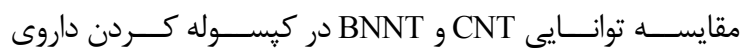




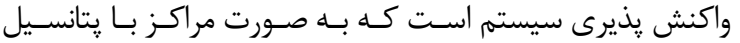

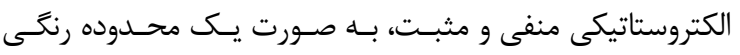

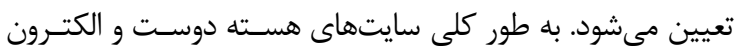

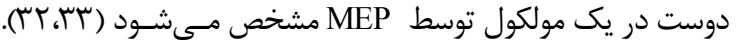

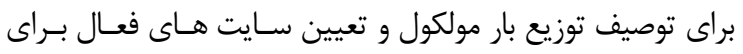

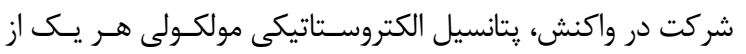

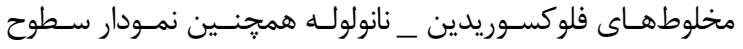

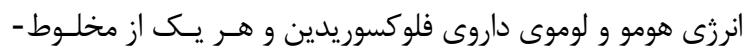

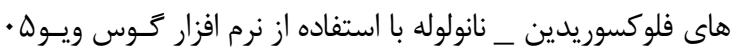

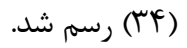

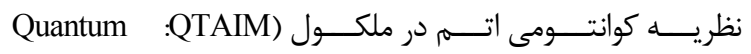

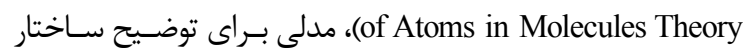

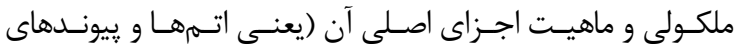

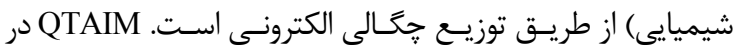

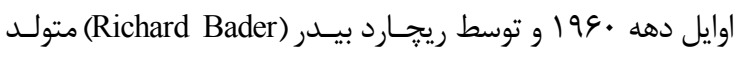

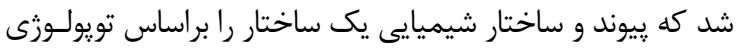

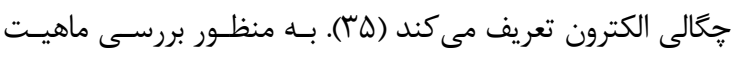

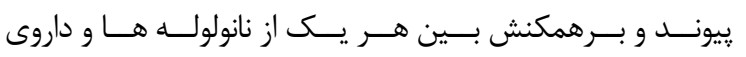

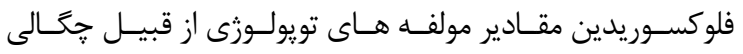
الكترونسى

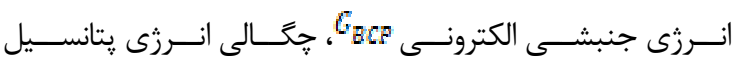
الكترونى

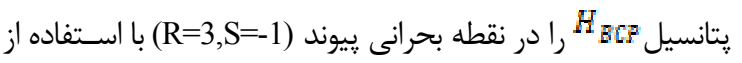

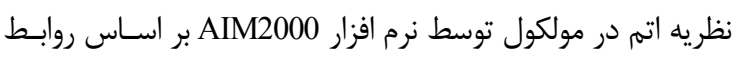
(1) الى (1) (1) محاسبه مىشود كه نتايج در جدولها آورده شـده

$$
\text { است. }
$$$$
\bar{V}^{2} \rho_{B C P}=\lambda_{1}+\lambda_{2}+\lambda_{3}=-4 \times L
$$

$$
G_{B C P}-\text { KEG }
$$

$V_{B C P}=-V I R$

$H_{B C P}=G_{B C P}+V_{B C P}$

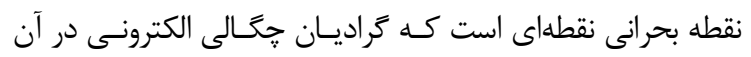

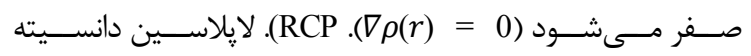
الكترون30

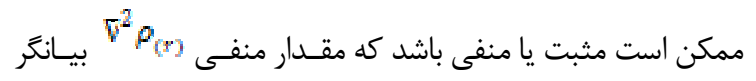

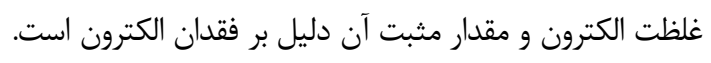

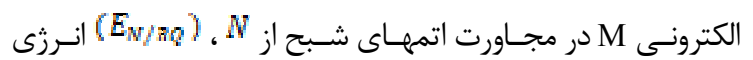
الكترونى N

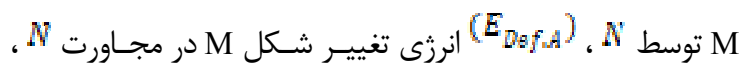

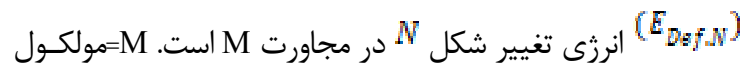

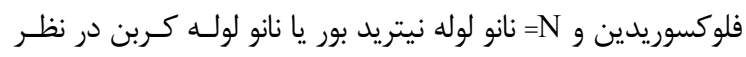
كرفته شده است. روش DFT، راهكار مناسبى جهت بر سرسى ويزَّى هاى سـاختارهاى

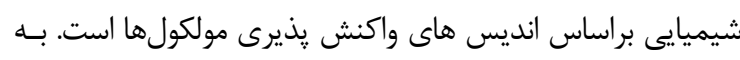

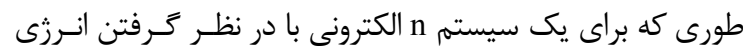
بالاترين اوربيتال مولكولى اشغال شده (

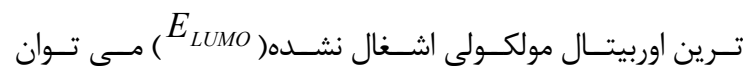

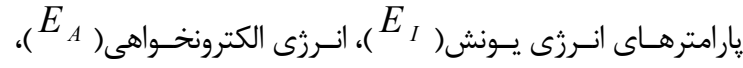

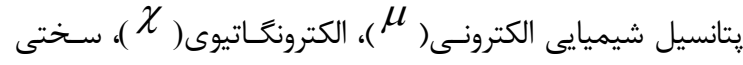

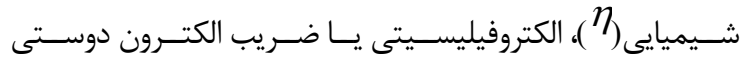

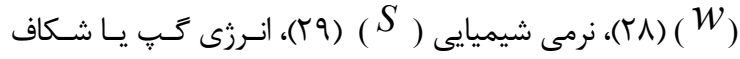

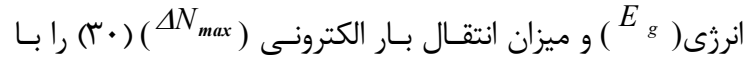
استفاده از روابط زير محاسبه كرد:

$$
\begin{aligned}
& E_{l}=-E_{\mathrm{How}} \\
& E_{A}=-E_{\text {LIWO }} \\
& \mu=\frac{\left[\mathrm{E}_{\text {HONON }}+\mathrm{E}_{\text {LMD }}\right]}{2}=-\mathrm{X} \\
& x=-\mu \\
& \eta=\frac{\left(E_{\text {LUMO }}-E_{\text {HQMD }}\right.}{2} \\
& w=\left(\frac{\mu^{2}}{2 \eta}\right) \\
& S=\frac{1}{2 \pi}
\end{aligned}
$$

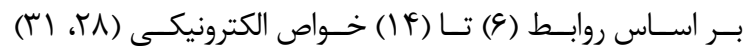

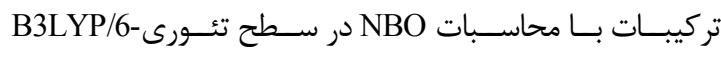
31G*

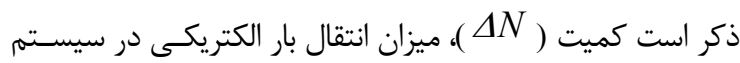

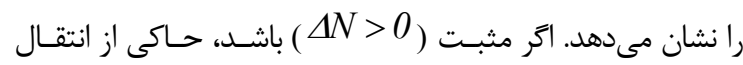
الكترون از جاذب به جذب شونده و اكر منفى (

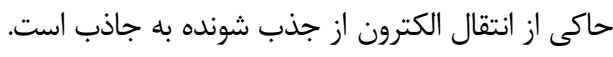

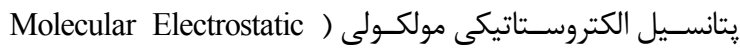

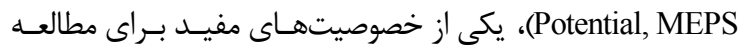




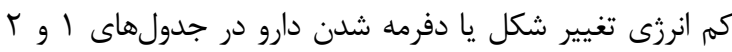

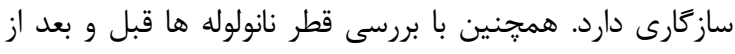

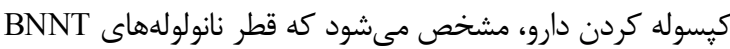

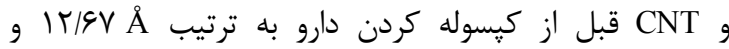

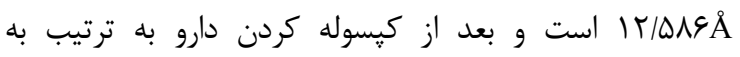

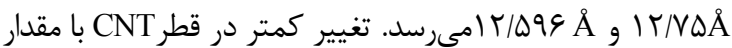
كمتر انرزى تغيير شكل يا دفرمه شدن CNT نسبت به BNA

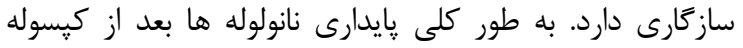

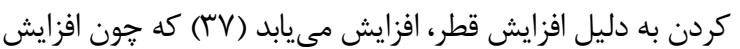
قطر نانولوله BNNT بيشتر ازCNT است، پِ بس بعد از كيسوله

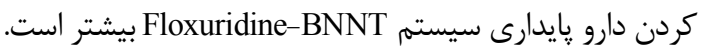

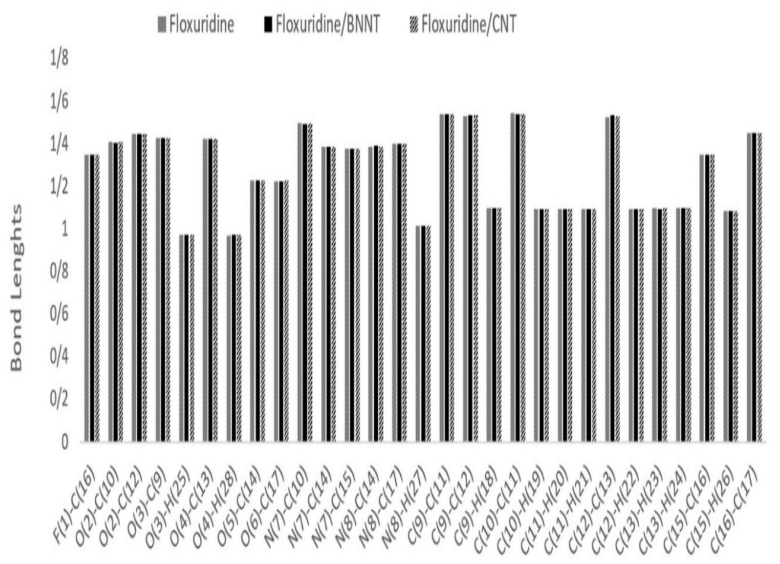

Bond

شكل r. مقايسه طول بيوند مولكول فلوكسوريدين قبل و بعد از

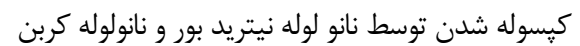

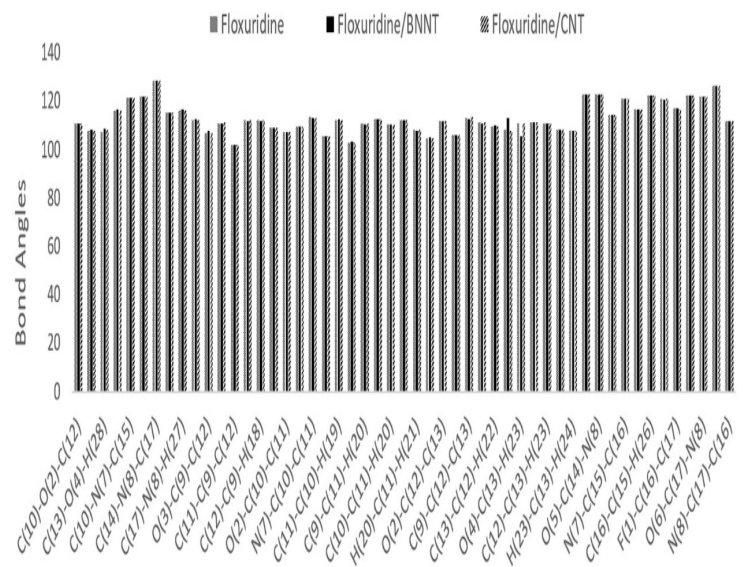

Bond

شكل r. مقايسه زاويه بِيوند مولكول فلوكسوريدين قبل و بعد از كيسوله شدن توسط نانو لوله نيتريد بور و نانولوله كربن 
جدول ا. مقادير انرزىهاى محاسبه شده در جذب فلوكسوريدين توسط نانولوله نيتريد بور

\begin{tabular}{lccccc}
\hline & \multicolumn{2}{c}{ SCF done energy at B3LYP/6-31G*/(kcal/mol) } & & \\
\hline Compounds & scf done energy & $\mathrm{U}(\mathrm{r})$ & $\Delta \mathrm{CP}$ & $\mathrm{E}$ ads & E def \\
\hline Floxuridine & -586748.7234 & $*$ & $*$ & $*$ & $*$ \\
Floxuridine-BQ(BNNT) & -586748.7215 & $*$ & $*$ & $*$ & -0.00181 \\
BNNT & -2714791.5809 & $*$ & $*$ & $*$ & $*$ \\
BNNT-BQ(Floxuridine) & -2714791.1143 & $*$ & $*$ & $*$ & -0.4665 \\
Floxuridine- BNNT & -3301547.2554 & -7.4195 & -0.4683 & -6.9512 & $*$ \\
\hline
\end{tabular}

جدول r. مقادير انرزىهاى محاسبه شده در جذب فلوكسوريدين توسط نانولوله كربن

\begin{tabular}{lccccc}
\hline & \multicolumn{2}{c}{ SCF done energy at B3LYP/6-31G*/(kcal/mol) } & & \\
\hline Compounds & scf done energy & $\mathrm{U}(\mathrm{r})$ & $\Delta \mathrm{CP}$ & $\mathrm{E}$ ads & $\mathrm{E}$ def \\
\hline Floxuridine & -586748.4661 & $*$ & $*$ & $*$ & $*$ \\
Floxuridine-BQ(CNT) & -586748.4382 & $*$ & $*$ & $*$ & -0.0278614 \\
CNT & -2596425.30201 & $*$ & $*$ & $*$ & $*$ \\
CNT-BQ(Floxuridine) & -2596425.24202 & $*$ & $*$ & $*$ & -0.0599899 \\
Floxuridine- CNT & -3183175.1251 & -1.4448 & -0.0878 & -1.3569 & $*$ \\
\hline
\end{tabular}

\begin{tabular}{|c|c|c|c|c|c|c|}
\hline \multicolumn{7}{|c|}{ B3LYP/6-31G* توابع ترموديناميكى تركيبات در سطح } \\
\hline Parameters & BNNT & $\mathrm{CNT}$ & Floxuridine & Floxuridine- BNNT & \multicolumn{2}{|c|}{ Floxuridine- CNT } \\
\hline $\mathrm{E}+\mathrm{G} /(\mathrm{kcal} / \mathrm{mol})$ & -2714238.923 & -2595805.997 & -586641.4321 & -3300883.742 & \multicolumn{2}{|c|}{-3182448.258} \\
\hline $\mathrm{E}+\mathrm{H} /(\mathrm{kcal} / \mathrm{mol})$ & -2714132.044 & -2595716.002 & -586604.1267 & -3300742.323 & \multicolumn{2}{|c|}{-3182321.639} \\
\hline $\mathrm{E}+\mathrm{T} /(\mathrm{kcal} / \mathrm{mol})$ & -2714132.637 & -2595716.595 & -586604.7191 & -3300742.915 & \multicolumn{2}{|c|}{-3182322.231} \\
\hline $\mathrm{E}+\mathrm{ZPE} /(\mathrm{kcal} / \mathrm{mol})$ & -2714178.462 & -2595754.36 & -586614.3325 & -3300798.96 & \multicolumn{2}{|c|}{-3182370.118} \\
\hline $\mathrm{S} /(\mathrm{Cal} / \mathrm{mol} . \mathrm{K})$ & 358.472 & 301.844 & 125.123 & 432.227 & \multicolumn{2}{|c|}{382.591} \\
\hline adsorption $/(\mathrm{kcal} / \mathrm{mol}) \mathrm{G} \Delta$ & $*$ & * & $*$ & -3.386 & \multicolumn{2}{|c|}{-0.828} \\
\hline$\Delta \mathrm{H}$ adsorption $/(\mathrm{kcal} / \mathrm{mol})$ & $*$ & $*$ & $*$ & -6.152 & \multicolumn{2}{|c|}{$\begin{array}{l}-0.020 \\
-1.509\end{array}$} \\
\hline $\mathrm{l} /(\mathrm{kcal} / \mathrm{mol})$ & * & $*$ & $*$ & -6.165 & \multicolumn{2}{|c|}{-1.425} \\
\hline$\Delta \mathrm{S}$ adsorption $/(\mathrm{Cal} / \mathrm{mol} . \mathrm{K})$ & $*$ & $*$ & $*$ & -51.368 & \multicolumn{2}{|c|}{-44.376} \\
\hline \multirow{2}{*}{\multicolumn{7}{|c|}{ فلوكسوريدين، دور اوربتالهاى دهيسته، اوربيتالهاى كَيرنده، انرزى رزونانس، اختلاف انرزى اوربيتالهاى بيشترين و كمترين انتقالات الكترونى در }} \\
\hline & & & & & & \\
\hline & \multicolumn{6}{|c|}{ 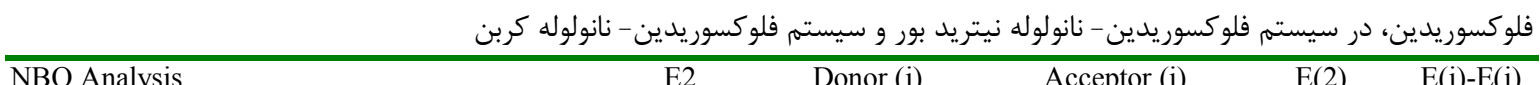 } \\
\hline \multicolumn{2}{|l|}{ within Floxuridine } & Max E2 & $\mathrm{LP}(1) \mathrm{N} 7$ & $\pi * \mathrm{O} \quad 5-\mathrm{C} \quad 14$ & 63.43 & 0.26 \\
\hline \multicolumn{2}{|c|}{ sum of E2 $=657.02 \mathrm{kcal} / \mathrm{mol}$} & Min E2 & $\mathrm{LP}(2) \mathrm{O} 2$ & $\sigma * \mathrm{C} 13-\mathrm{H} 24$ & & 0.75 \\
\hline \multicolumn{2}{|c|}{ within Floxuridine in Floxuridine-BNNT } & Max E2 & $\mathrm{LP}(1) \mathrm{N} 7$ & $\pi * \mathrm{O} \quad 5-\mathrm{C} 14$ & & 0.27 \\
\hline \multicolumn{2}{|c|}{ sum of E2 $=654.7 \mathrm{kcal} / \mathrm{mol}$} & Min E2 & $\sigma \mathrm{N} 8-\mathrm{H} 20$ & $\sigma * \mathrm{O} \quad 5-\mathrm{C} 14$ & $\begin{array}{c}61.15 \\
0.5\end{array}$ & 1.23 \\
\hline \multicolumn{2}{|l|}{ Floxuridine to BNNT } & Max E2 & LP (1) F 1 & $\pi * \mathrm{~B} 35-\mathrm{N} 37$ & & 1.1 \\
\hline \multicolumn{2}{|l|}{ sum of E2 $=8.28 \mathrm{kcal} / \mathrm{mol}$} & Min E2 & LP (1) F 1 & $\sigma * \mathrm{~B} 35-\mathrm{N} 36$ & & 1.53 \\
\hline \multicolumn{2}{|l|}{ BNNT to Floxuridine } & Max E2 & $\pi \mathrm{B} 93-\mathrm{N} 95$ & $\sigma * \mathrm{O} \quad 3-\mathrm{H} \quad 18$ & $\begin{array}{l}0.05 \\
1.56\end{array}$ & 0.73 \\
\hline \multicolumn{2}{|c|}{ sum of $\mathrm{E} 2=1.91 \mathrm{kcal} / \mathrm{mol}$} & Min E2 & $\pi$ B $118-\mathrm{N} 119$ & $\sigma * \mathrm{C} 13-\mathrm{H} 27$ & 0.05 & 0.73 \\
\hline \multicolumn{2}{|c|}{ within Floxuridine in Floxuridine-CNT } & Max E2 & $\mathrm{LP}(1) \mathrm{N} 8$ & $\pi * \mathrm{O} \quad 6-\mathrm{C} \quad 17$ & 56.02 & 0.27 \\
\hline \multicolumn{2}{|c|}{ sum of E2 $=529.07 \mathrm{kcal} / \mathrm{mol}$} & Min E2 & $\sigma \mathrm{C} 9-\mathrm{C} 11$ & $\sigma * \mathrm{C} 10-\mathrm{C} 11$ & 0.5 & 0.95 \\
\hline \multicolumn{2}{|l|}{ CNT to Floxuridine } & Max E2 & $\pi \mathrm{C} 66-\mathrm{C} 67$ & $\sigma * \mathrm{O} \quad 4-\mathrm{H} \quad 28$ & 0.19 & 0.71 \\
\hline sum of E2 $=0.53 \mathrm{kcal} / \mathrm{mol}$ & & Min E2 & $\pi$ C $100-$ C 108 & $\sigma * \mathrm{C} 11-\mathrm{H} 21$ & 0.06 & 0.71 \\
\hline
\end{tabular}

Sum of Electronic and Thermal) آنتاليى (Enthalpies Sum of Electronic and Gibbs free ) כيبس (energy

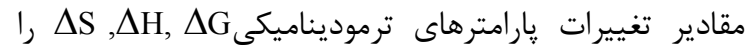
براى داروى فلوكسوريدين، نانو لوله نيتريد بور، نانولوله كربن،

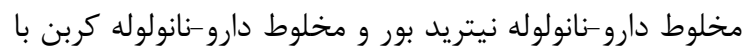

\section{توابع ترموديناميكى در محيط آب}

يارامترهاى ترموديناميكى از قبيل مجموع انرزى الكترونى و Sum of Electronic and Thermal Free ( انرزى گرمايى ناشى از حركات انتقالى، ارتعاشى و زرخشى (Energies ذرات (El Sum of Electronic and (Thermal Free Energies 
هاى رزونانسى از سوى نانولوله نيتريد بور به فلوكسوريدين برابر E2=1.91 kcal/mol است. در نتيجه زمانى كه مولكول دارو در كنار نانولوله نيتريد بور قرار مى گيرد رزونانس و جريان الكترون از دارو به سمت نانولوله بيشتر از نانولوله به سمت دارو است و مجموع انرزىهاى رزونانسى از سوى نانولوله كربن به

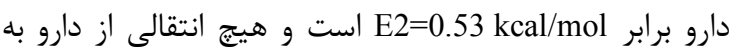
نانو لوله كربن انجام نمىشود و اين نيز تاييدى بر بهتر بودن جاذب BNNT نسبت به CNT براى داروى فلوكسوريدين

\section{خواص الكترونيكى}

اثر برهمكنش نانولوله نيتريد بور (V-Vو (9) و نانولوله كربن (V)

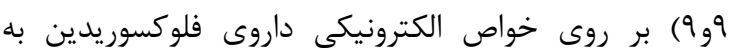
كمك محاسبات NBO در سطح B3LYP/6-31G بر برسى و مطالعه شد و انديسهاى واكنش يذيرى بر اساس روابط 9 الى

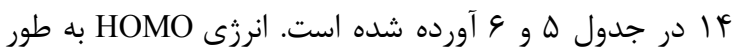

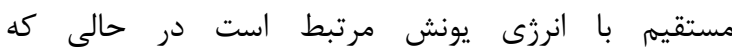
انرزى LUMO با الكترون خواهى مرتبط است و سختى شيميايى مربوط به شكاف انرزى بين HOMO و

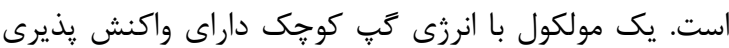
شيميايى بالا و وايدارى سينتيكى كم است و يك مولكول نرم است. نتايج حاصل از محاسبات NBO نشان مىدهد كه گي انرزى فلوكسوريدين در مخلوط فلوكسوريدين-نانو لوله نيتريد بور (Eg=5.2733 eV, S= $\left.0.1896 \mathrm{eV}^{-1}\right)$ و گ

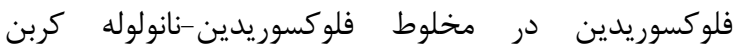
نسبت به فلوكسوريدين (Eg=5.2523 eV, S=0.1904 eV'-1) تك (Eg=5.248 eV, S=0.1905 eV طرفى، واكنش يذيرى يك مولكول به گٍ انرزى آن مرتبط و

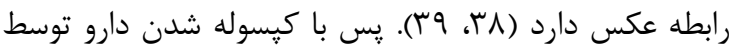
نانو لوله نيتريد بور نرمى و واكنش يذيرى دارو كمتر شده و

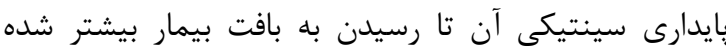
است و جون نرمى فلوكسوريدين در كنار BNNT كمتر از نرمى فلوكسوريدين در كنار نانو CNT است، مىتوان كفت يايدارى دارو كنار BNNT بيشتر است و BNNT جاذب بهترى براى اين دارو است. از طرفى با كيسوله شدن دارو توسط نانولولهها، با كاهش گٍ انرزى مخلوط فلوكسوريدين - نانو لوله نيتريد بور ( Eg=5.2001 eV, S= $\left.0.1923 \mathrm{eV}^{-1}\right) ،$ همجنين مخلوط فلوكسوريدين - نانو لوله كربن مى eV, S=0.5502 eV'-1) شده، ولى در مخلوط Floxuridine-CNT به دليل افزايش قابل توجه در نرمى آن، مى نوان نتيجه گرفت كه يايدارى
ستفاده از سطح تئورى B3LYP/6-31G به دست آورديم كه نتايج در جدول ب آورده شده است. مطابق جدول r علاوه بر انرزى جذب، مقاديرتغييرات توابع ترموديناميكى مخلوط دارونانولوله نيتريد بور نسبت به مخلوط دارونانولوله كربن كوجگتر و منفىتر است، كه اين مقادير انرزى، گوياى كاهش بوري

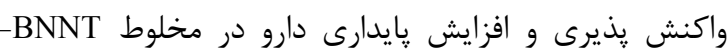
نسبت به مخلوط Floxuridine يُ BNNT جاذب بهترى براى دارو نسبت به CNT است. به

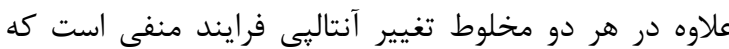
نشان مى دهد فرايند جذب گرماده بوده و مساعد است.

\section{تجزيه و تحليل اوربيتالهاى ييوندى طبيعى (NBO)} به منظور مطالعه اثـر الكتـرون هنـــــى و و الكتـرون

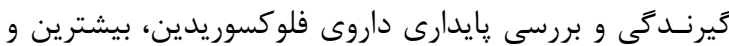

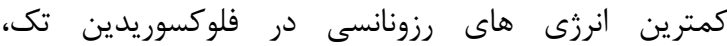
فلوكسوريدين كيسوله شده و در انتقالات الكترونى ازئ فلوكسوريدين به نانو لوله ها و بالعكس به كمك محاسبات NBO جدول F آورده شده است. مجموع ساير انرزىهاى رزونانسى

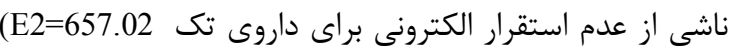
kcal/mol) و در داروى كيسوله شده توسط نانو (E2=654.7 kcal/mol)

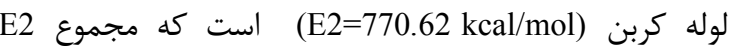
فلوكسوريدين كيسوله شده توسط نانولوله نيتريد بور نسبت به فلوكسوريدين تك كاهش يافته و اين نشان مىدهد كه دارو درگير رزونانس الكترونى با نانولوله شده و با قرار گرفتن در ميدان نانو لوله به صورت ييش دارو در مىآيد، يعنى واكنش

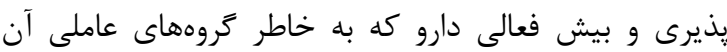
است در رزونانس الكترونى با نانو كاهش داده مئى بـود و و با اين كار دارو به يك باره در بدن باز و آزاد نمىشود و زمان بيشترى

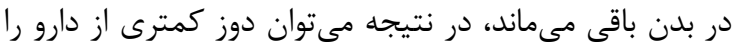

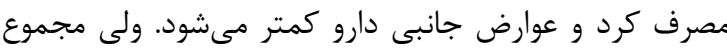
E2 فلوكسوريدين كيسوله شده توسط نانولوله كربن نسبت به فلوكسوريدين تك افزايش يافته و اين نشان مىدهد كه دارو در كنار CNT كمتر دركير رزونانس الكترونى با نانولوله شده و همان طور كه از مقدار نرمى آن يس از كيسوله شدن مشخص است، نرمى و واكنش يذيرى آن تغيير جندانى نكرده و دارو

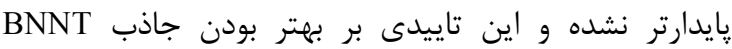
نسبت به CNT براى داروى فلوكسوريدين هست. همجنين مجموع انرزىهاى رزونانسى از سوى فلوكسوريدين

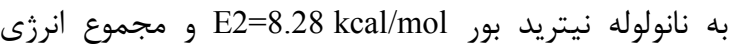




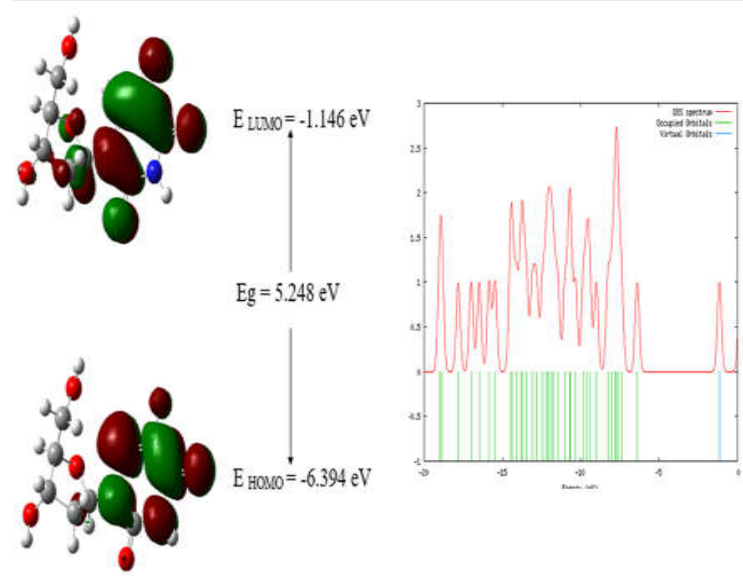

شكل F. دياكرام اوربيتالهاى HOMO و LUMO و نمودار B3LYP/6-31G* داروى فلوكسوريدين در سطح (DOS)

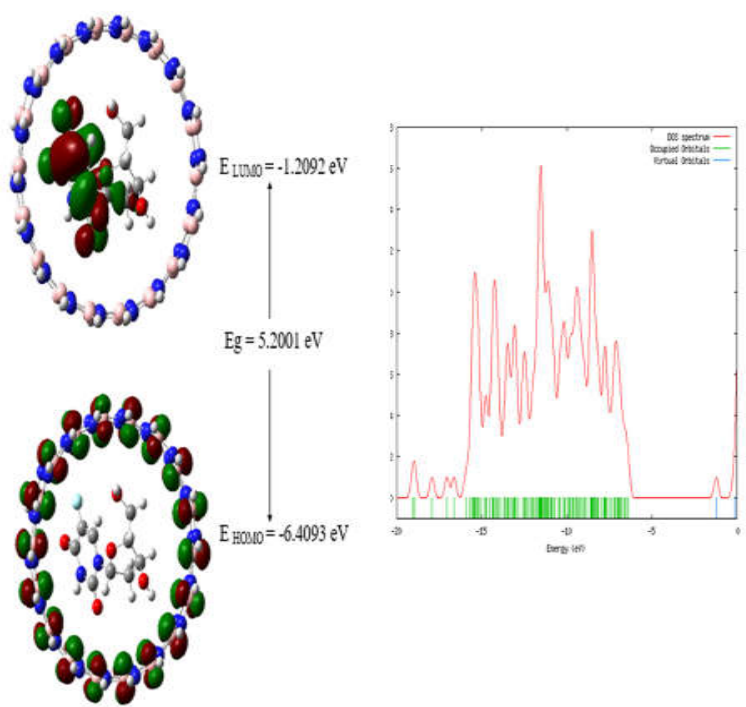

شكل ه. دياگرام اوربيتالهاى HOMO و LUMO و نمودار B3LYP/6-31G* در سطح Floxuridine-BNNT (DOS)

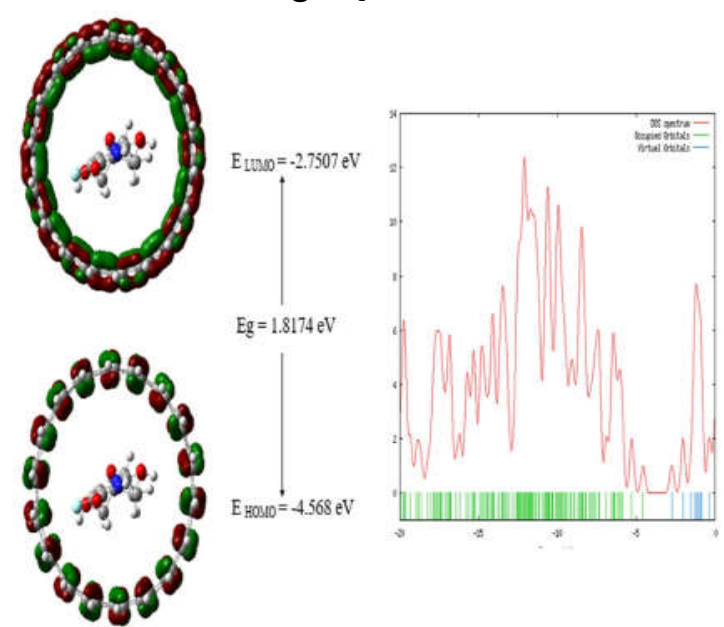

شكل \&. دياكرام اوربيتالهاى HOMO و LUMO و نمودار B3LYP/6-31G* در سطح Floxuridine-CNT (DOS)
سينتيكى آن كمتر از مخلوط Floxuridine-BNNT است و ممكن است قبل از رسيدن دارو به بافت بيمار دركير واكنش

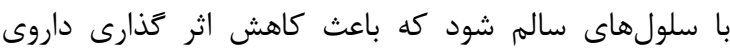
فلوكسوريدين در درمان مىشود؛ پِ مى توان كَفت مخلوط

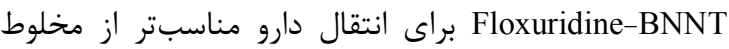
Floxuridine-CNT نانولوله يس از كيسوله كردن دارو به مقدار جزئى افزايش يافت، يارامتر سختى هر دو افزايش يافت و واكنش يذيرى هر إنى

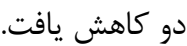
اوربيتالهاى مرزى يعنى اوربيتالهاى HOMO و LUMO مولكولها نقش موثرى در واكنش دارند. تجزيه و تحليل

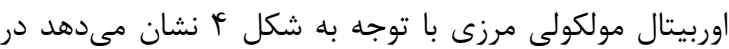
مولكول فلوكسوريدين اوربيتال HOMO به طور عمده بر روى اتمهاى اكسيرن و فلوئور و اتم هاى حلقه هكًزاتونال به جز

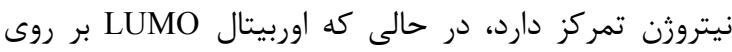

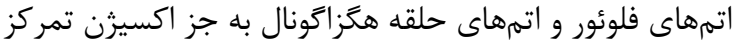

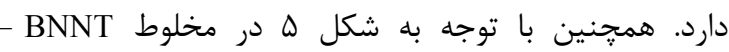
HOMO بر روى فلوكسوريدين و Floxuridine اوربيتال LUMO بر روى نانو لوله BNNT متمركز شده است.

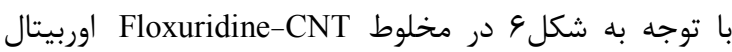

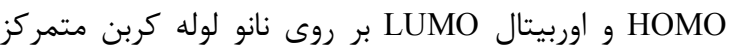
شده است. همجنين لازم به ذكر است كه ميزان كميت انتقال

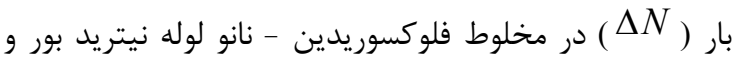

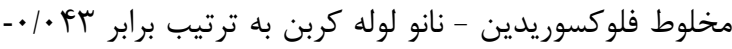

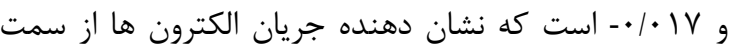
دارو به سمت نانولولهها و بر قرارى رزونانس الكترونى بين دارو و نانولولهها است. همجنين ممان دو قطبى BNNT و

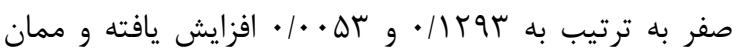
دوقطبى دارو درمخلوط فلوكسوريدين - نانو لوله نيتريد بور از

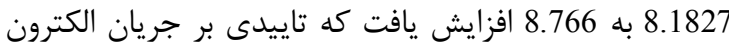

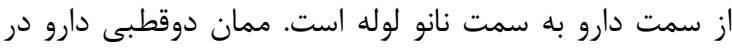

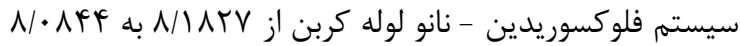
كاهش يافت كه اين نشان ميدهد كه دارو در كنار

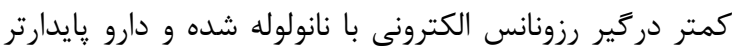
نشده و اين تاييدى بر بهتر بودن جاذب BNNT نسبت به به CNT براى داروى فلوكسوريدين است. 
CNT- كمتر است و در مخلوط Floxuridine-BNNT

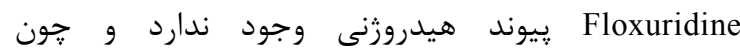

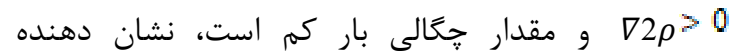
برهمكنشهاى واندروالسى بين نانولوله كربن و دارو است. همجنين با توجه به مقادير م و و Floxuridine-CNT و Floxuridine فلوكسوريدين با نانولوله نيتريد بور قوىتر است.
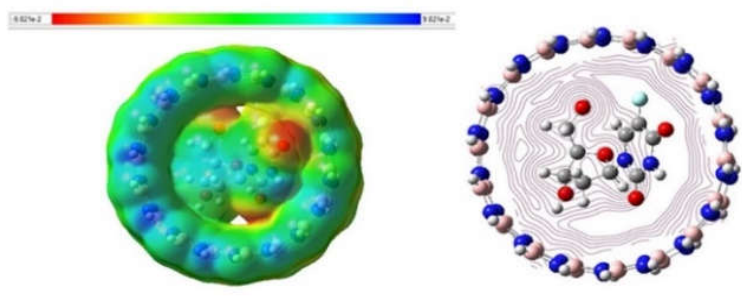

الف)

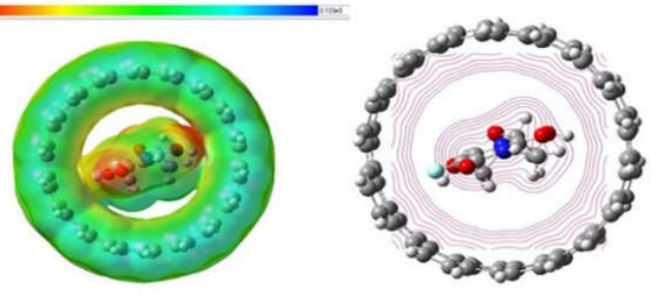

(ب

شكل V. شمايى از يتانسيل الكتروستاتيكى مولكولى (MEP)

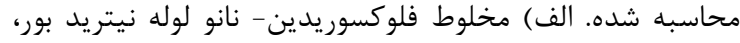

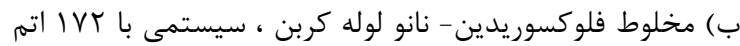

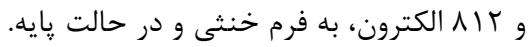

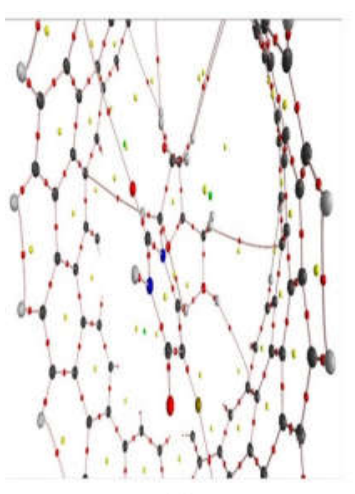

(ب

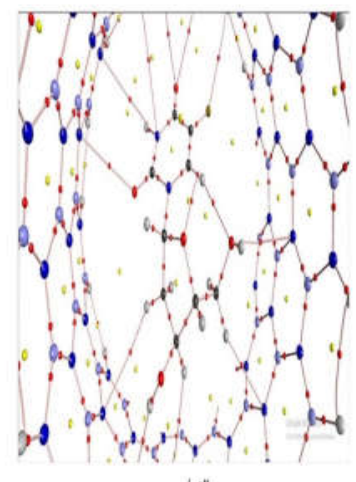

(ال)

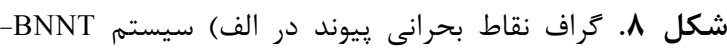
Floxuridine
بتانسيل الكتروستاتيكى مولكول (MEP)

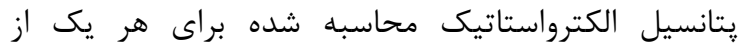

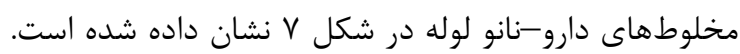
در مخلوط Floxuridine-BNNT بر روى اتمهاى نيتروزن

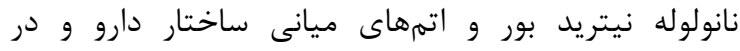

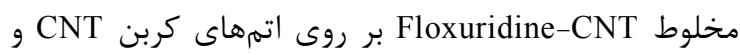

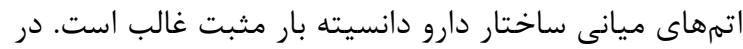
هر دو مخلوط بر روى اتم هاى اكسيزن و فلوئور دارو،

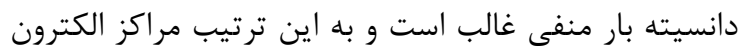

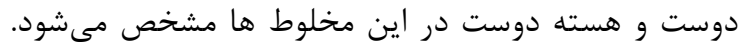

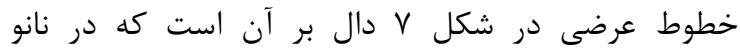

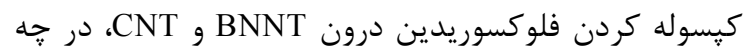

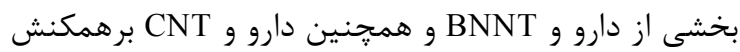

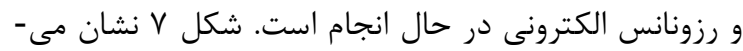

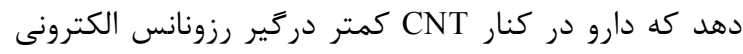
با نانو لوله كربن شده است.

نظريه كوانتومى اتم در مولكول (QTAIM)

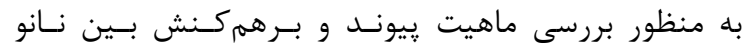

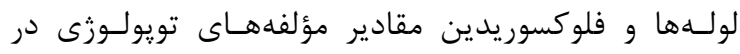

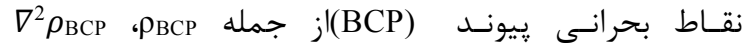

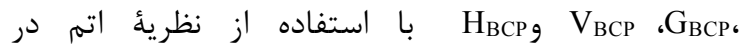

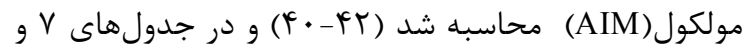
^ خرد آورى شد. كرافهاى مولكولى در نقاط بحرانى مخلوط Floxuridine-CNT F Floxuridine -BNNT شكل ^ نشان داده شده است كه با توجه به اين شكلها،

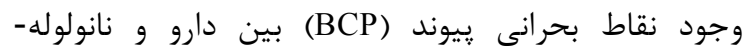
هاى BNNT و CNT، شواهدى براى برهمكنش بين دارو و بران

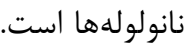

با توجه به يارامترهاى تويولوزى مخلوط BNNT-

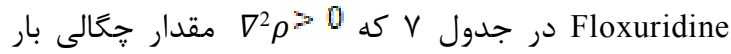
كم است، نشان دهنده برهمكنشهاى واندروالسى و و

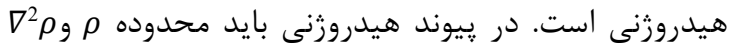

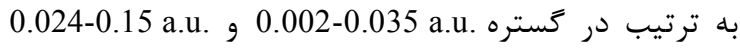
باشد و هر جه م مبيشتر و هيدروزنى قوىتر است. پييوند هيدروزنى

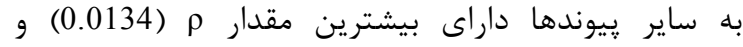
بيشترين D2 D ( 0.0413) است، يس نسبت به ساير يِيوندها

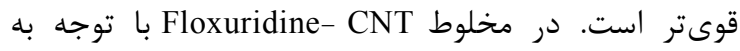
نتايج يارامترهاى تويولوزى در جدول 1 تعداد برهمكنش-

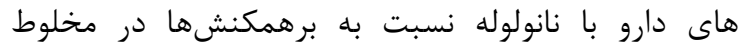




\begin{tabular}{|c|c|c|c|c|c|}
\hline \multirow[t]{2}{*}{ Property / B3LYP/6-31g* } & \multicolumn{5}{|c|}{ Compounds } \\
\hline & Floxuridine & BNNT & Floxuridine-BNNT & Floxuridine -BQ & BNNT-BQ \\
\hline ELUMO / (eV) & -1.1464 & -0.1186 & -1.2092 & -1.1423 & -0.1186 \\
\hline Еномо / (eV) & -6.3944 & -6.4218 & -6.4093 & -6.4156 & -6.4267 \\
\hline Ionization potential $(E I) /(\mathrm{eV})$ & 6.3944 & 6.4218 & 6.4093 & 6.4156 & 6.4267 \\
\hline Electron affinity $(E A /(\mathrm{eV}))$ & 1.1464 & 0.1186 & 1.2092 & 1.1423 & 0.1186 \\
\hline Energy gap $(E g) /(\mathrm{eV})$ & 5.2480 & 6.3032 & 5.2001 & 5.2733 & 6.3081 \\
\hline Chemical potential $(\mu) /(\mathrm{eV})$ & -3.7704 & -3.2702 & -3.8093 & -3.7789 & -3.2727 \\
\hline Electronegativity $(\chi) /(\mathrm{eV})$ & 3.7704 & 3.2702 & 3.8093 & 3.7789 & 3.2727 \\
\hline Global hardness $(\eta) /(\mathrm{eV})$ & 2.6240 & 3.1516 & 2.6001 & 2.6366 & 3.1540 \\
\hline Global electrophilicity $(\omega) /(\mathrm{eV})$ & 2.7088 & 1.6967 & 2.7904 & 2.7080 & 1.6979 \\
\hline Chemical softness $(\mathrm{S}) /(\mathrm{eV}-1)$ & 0.1905 & 0.1586 & 0.1923 & 0.1896 & 0.1585 \\
\hline Dipole Moment / (Debye) & 8.1827 & 0.0000 & 8.9819 & 8.766 & 0.1293 \\
\hline$\Delta \mathrm{N} \max$ & \multicolumn{5}{|c|}{-0.043} \\
\hline
\end{tabular}

\begin{tabular}{|c|c|c|c|c|c|}
\hline & 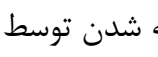 & 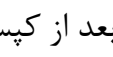 & فلو كسوريدين قبر & ب هاى واكنش يذ & جدول 9. ان \\
\hline \multirow[t]{2}{*}{ Property / B3LYP/6-31g* } & \multicolumn{5}{|c|}{ Compounds } \\
\hline & Floxuridine & CNT & Floxuridine-CNT & Floxuridine $-\mathrm{BQ}$ & CNT-BQ \\
\hline ELUMO / (eV) & -1.1464 & -2.7422 & -2.7507 & -1.1496 & -2.7414 \\
\hline $\mathrm{EHOMO} /(\mathrm{eV})$ & -6.3944 & -4.5590 & -4.5680 & -6.4020 & -4.5593 \\
\hline Ionization potential $(\mathrm{EI}) /(\mathrm{eV})$ & 6.3944 & 4.5590 & 4.5680 & 6.4020 & 4.5593 \\
\hline Electron affinity $(\mathrm{EA} /(\mathrm{eV}))$ & 1.1464 & 2.7422 & 2.7507 & 1.1496 & 2.7414 \\
\hline Energy gap $(\mathrm{Eg}) /(\mathrm{eV})$ & 5.2480 & 1.8168 & 1.8174 & 5.2523 & 1.8179 \\
\hline Chemical potential $(\mu) /(\mathrm{eV})$ & -3.7704 & -3.6506 & -3.6593 & -3.7758 & -3.6504 \\
\hline Electronegativity $(\chi) /(\mathrm{eV})$ & 3.7704 & 3.6506 & 3.6593 & 3.7758 & 3.6504 \\
\hline Global hardness $(\eta) /(e V)$ & 2.6240 & 0.9084 & 0.9087 & 2.6262 & 0.9090 \\
\hline Global electrophilicity $(\omega) /(\mathrm{eV})$ & 2.7088 & 7.3354 & 7.3683 & 2.7143 & 7.3299 \\
\hline Chemical softness $(\mathrm{S}) /(\mathrm{eV}-1)$ & 0.1905 & 0.5504 & 0.5502 & 0.1904 & 0.5501 \\
\hline Dipole Moment / (Debye) & 8.1827 & 0.0000 & 7.4913 & 8.0844 & 0.0053 \\
\hline$\Delta \mathrm{N} \max$ & & & -0.017 & & \\
\hline
\end{tabular}

\begin{tabular}{|c|c|c|c|c|c|}
\hline \multicolumn{6}{|c|}{ جدول V. پارامترهاى تويولوزى حاصل از آناليز QTAIM براى سيستم Floxuridine-BNNT } \\
\hline \multicolumn{6}{|c|}{ جارامترهاى تويولوزى سيستم Floxuridine-BNNT بر حسب a.u. } \\
\hline Bond & $\rho$ & $\nabla_{2}^{2} \rho$ & $V(r)$ & $G(r)$ & $H(r)$ \\
\hline F1- N43 & 0.0065 & 0.0263 & -0.0042 & 0.0054 & -0.0011 \\
\hline O6-H141 & 0.0021 & 0.0085 & -0.0008 & 0.0015 & -0.0006 \\
\hline O6-N50 & 0.0033 & 0.0129 & -0.0021 & 0.0026 & -0.0005 \\
\hline N8-B58 & 0.0015 & 0.0064 & -0.0007 & 0.0011 & -0.0004 \\
\hline N8-N67 & 0.0014 & 0.0062 & -0.0007 & 0.0011 & -0.0004 \\
\hline O5-N68 & 0.0043 & 0.0161 & -0.0026 & 0.0033 & -0.0006 \\
\hline H24-N85 & 0.0017 & 0.0247 & -0.0006 & 0.0010 & -0.0004 \\
\hline H18-N95 & 0.0134 & 0.0413 & -0.0088 & 0.0096 & -0.0007 \\
\hline H21-N101 & 0.0031 & 0.0109 & -0.0013 & 0.0020 & -0.0007 \\
\hline H27-N119 & 0.0044 & 0.0140 & -0.0020 & 0.0027 & -0.0007 \\
\hline O4-N126 & 0.0034 & 0.0135 & -0.0020 & 0.0026 & -0.0006 \\
\hline
\end{tabular}

مخلوط Floxuridine-CNT نسبت Floxuridine-BNNT منفىتر است؛ بنابراين مخلوط Floxuridine-BNNT مخايدارتر

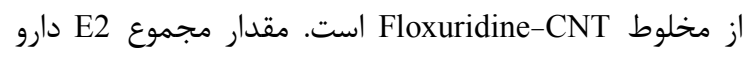
زمانى كه در كنار BNNT قرار گرفت، كاهش يافت؛ يعنى مقد مجنى الكترونهاى غير مستقر دارو در رزونانس الكترونى با نانولوله

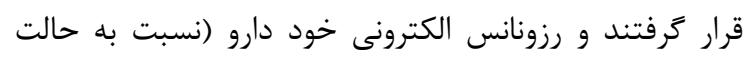

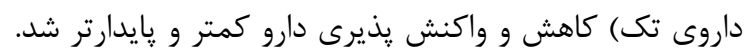

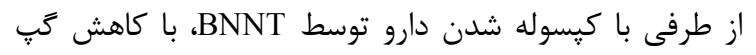

$$
\begin{aligned}
& \text { در : يزوهش حاضر اثر برهمكنش غيرييوندى داروى }
\end{aligned}
$$

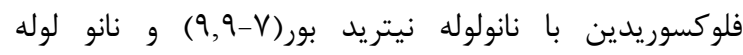

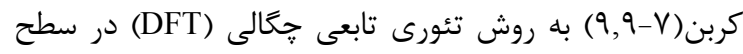

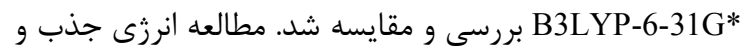

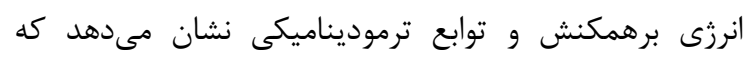

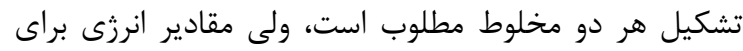




\begin{tabular}{|c|c|c|c|c|c|}
\hline \multicolumn{6}{|c|}{ هارامترهاى تويولوزى سيستم Floxuridine-CNT بر حسب u. } \\
\hline Bond & $\rho$ & $\nabla_{2} \rho$ & $V(r)$ & $G(r)$ & $H(r)$ \\
\hline F1-C55 & 0.0044 & 0.0204 & -0.0031 & 0.0041 & -0.0010 \\
\hline O5-C112 & 0.0011 & 0.006 & -0.0006 & 0.0011 & -0.0004 \\
\hline H19-C125 & 0.0004 & 0.0016 & -0.0001 & 0.0003 & -0.0001 \\
\hline $\mathrm{H} 21-\mathrm{C} 100$ & 0.0018 & 0.006 & -0.0007 & 0.0011 & -0.0003 \\
\hline H20-C93 & 0.0003 & 0.0016 & -0.0001 & 0.0003 & -0.0001 \\
\hline H18-C90 & 0.0002 & 0.0012 & -0.0001 & 0.0002 & -0.0001 \\
\hline $\mathrm{H} 23-\mathrm{C} 75$ & 0.0004 & 0.002 & -0.0002 & 0.0003 & -0.0001 \\
\hline H28-C59 & 0.0038 & 0.0136 & -0.0017 & 0.0026 & -0.0008 \\
\hline $\mathrm{H} 25-\mathrm{C} 115$ & 0.0024 & 0.0088 & -0.0009 & 0.0015 & -0.0006 \\
\hline
\end{tabular}

$$
\begin{aligned}
& \text { فلوكسوريدين با هر دو نانولوله نشان مىدهد كه BNNT حامل } \\
& \text { بهترى براى داروى ضد سرطان فلوكسوريدين در رساندن دارو }
\end{aligned}
$$

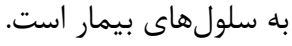

$$
\begin{aligned}
& \text { تقدير و تشكر } \\
& \text { مراتب قدردانى خود را از مسئولين دانشكاه آزاد واحد تهران } \\
& \text { مركزى كه در انجام ايـن تحقيـق مـا را يـارى رساندند، اعلام } \\
& \text { مى داريم. }
\end{aligned}
$$

\section{REFERENCES}

1. Power DG, Kemeny NE. The role of Floxuridine in metastatic liver disease. Mol Cancer Ther 2009; 8:1015-1025.

2. Stefano GDi, Busi C, Fiume L. Floxuridine coupling with lactosaminated human albumin to increase drug efficacy on liver micrometastases. Dig Liver Dis 2002; 34:439-446.

3. Shun-rong J, Chen L, Bo Z, Feng Y, Jin X, Jiang L, et al. Carbon nanotubes in cancer diagnosis and therapy. Biochim Biophys Acta 2010; 1806:29-35.

4. Bertrand N, Leroux JC. The journey of a drug-carrier in the body: an anatomo-physiological perspective. J Control Release 2012; 161:152-163.

5. Karimi M, Ghasemi A, Sahandi Zangabad P, Rahighi R, Moosavi Basri SM, Mirshekari H, et al. Smart micro/nanoparticles in stimulus-responsive drug/gene delivery systems. Chem Soc Rev 2016; 45:1457-1501.

6. Ferrari M. Cancer nanotechnology: opportunities and challenges. Nat Rev Cancer 2005; 5:161-71.

7. Jain KK. Applications of nanobiotechnology in clinical diagnostics. Clin Chem 2007; 53:2002-2009.

8. Kim PS, Djazayeri S, Zeineldin R. Novel nanotechnology approaches to diagnosis and therapy of ovarian cancer. Gynecol Oncol 2011; 120:393-403.

9. Kostarelos K, Bianco A, Prato M. Promises, facts and challenges for carbon nanotubes in imaging and therapeutics. Nat Nanotechnol 2009; 4:627-33.

10. Bawa R. NanoBiotech 2008: Exploring global advances in nanomedicine. Nanomedicine 2009; 5:5-7.

11. Park J, Wrzesinski SH, Stern E, Look M, Criscione J, Ragheb R, et al. Combination delivery of TGF- $\beta$ inhibitor and IL-2 by nanoscale liposomal polymeric gels enhances tumour immunotherapy. Nat Mater 2012; 11:895-905.

12. Adlakha-Hutcheon G, Bally MB, Shew CR, Madden TD. Controlled destabilization of a liposomal drug delivery system enhances mitoxantrone antitumor activity. Nat Biotechnol 1999; 17:775-779.

13. Liu Z, Cai W, He L, Nakayama N, Chen K, Sun X, et al. In vivo biodistribution and highly efficient tumour targeting of carbon nanotubes in mice. Nat Nanotechnol 2007; 2:47-52.

14. Liu Z, Tabakman S, Welsher K, Dai H. Carbon nanotubes in biology and medicine: in vitro and in vivo detection, imaging and drug delivery. Nano Res 2009; 2:85-120. 
15. Prato M, Kostarelos K, Bianco A. Functionalized carbon nanotubes in drug design and discovery. Acc Chem Res 2008; 41:60-68.

16. Blase X, Rubio A, Louie SG, Cohen ML. Stability and band gap constancy of boron nitride nanotubes. Europhys Lett 1994; 28:335-340.

17. Ciofani G, Raffa V, Menciassi A, Dario P. Preparation of boron nitride nanotubes aqueous dispersions for biological applications. J Nanosci Nanotechnol 2008; 8:6223-6231.

18. Ricotti L, Fujie T, Vazao H, Ciofani G, Marotta R, Brescia R, et al. Boron nitride nanotube-mediated stimulation of cell co-culture on micro-engineered hydrogels. PLoS One 2013; 8:71707.

19. Ciofani G, Raffa V, Menciassi A, Cuschieri A. Cytocompatibility, interactions, and uptake of polyethyleneiminecoated boron nitride nanotubes by living cells: confirmation of their potential for biomedical applications. Biotechnol Bioeng 2008; 101:850-858.

20. Turcoa SD, Ciofanib G, Cappelloc V, Gemmic M, Cervellia T, Saponaroa C, et al. Cytocompatibility evaluation of glycol-chitosan coated boron nitride nanotubes in human endothelial cells. Colloids and Surfaces B: Biointerfaces 2013; 111:142-149.

21. Ciofania G, Dantib S, Nitti S, Mazzolaia B, Mattolia V, Giorgid M. Biocompatibility of boron nitride nanotubes: An up-date of in vivo toxicological investigation. Int J Pharm 2013; 444:85- 88.

22. 22.Chen X, Wu P, Rousseas M, Okawa D, Gartner Z, Zettl A, et al. Boron nitride nanotubes are noncytotoxic and can be functionalized for interaction with proteins and cells. J Am Chem Soc 2009; 131:890-891.

23. Ciofania G, Raffaa V, Menciassia A, Cuschieria A. Boron nitride nanotubes: An innovative tool for nanomedicine. Nano Today 2009;4:8-10.

24. Hughes GA. Nanostructure-mediated drug delivery. Nanomed 2005; 1:22-30.

25. Mejri1 A, Vardanega D, Tangour1 B, Gharbi T, Picaud F. Encapsulation into carbon nanotubes and release of anticancer cisplatin drug molecule. J Phys Chem B 2015; 119:604-611.

26. Khalifi ME, Duverger E, Gharbi T, Boulahdour H, Picaud F. Theoretical demonstration of the potentiality of boron nitride nanotubes to encapsulate anticancer molecule. Phys Chem Chem Phys 2015; 17:30057-30064.

27. Frisch MJ, Trucks GW, Schlegel HB, Scuseria GE, Robb MA, Cheeseman JR, et al, Editors. Gaussian 09, Revision A.01. Wallingford: Gaussian, Inc.; 2009.

28. Shahab S, Filippovich L, Sheikhi M, Kumar R, Dikusar E, Yahyaei H, et al. Polarization, excited states, trans-cis properties and anisotropy of thermal and electrical conductivity of the 4-(phenyldiazenyl)aniline in PVA matrix. J Mol Struct 2017; 1141:703-709.

29. Shahab, S, Filippovich L, Sheikhi M, Yahyaei H, Aharodnikova M, Kumar R, et al. Spectroscopic (Polarization FT-IR ExcitedState UV/Vis and 1H NMR) and thermophysical investigations of new synthesized azo dye and its application in polarizing film. J Mater Synth Process 2017; 5:17-23.

30. Parr RG, Pearson RG, Absolute hardness: companion parameter to absolute electronegativity. J Am Chem Soc $1983 ; 105: 7512-7516$

31. Shahab S, Sheikhi M, Filippovich L, Dikusar Anatol'evich E, Yahyaei H. Quantum chemical modeling of new derivatives of (E,E)-azomethines: synthesis, spectroscopic (FT-IR, UV/Vis, polarization) and thermophysical investigations. J Mol Struct 2017; 1137:335-348.

32. Masnabadi N, Nori-Shargh D, Azarakhshi F, Zamani Ganji H, Abbasi M, Karamad S, et al. Hybrid-Density Functional Theory, MO Study, and NBO Interpretation of Conformational Behaviors of 2-Halo-1,3-Dioxanes and Their Dithiane and Diselenane Analogs. Phosphorus Sulfur Silicon Relat Elem 2012; 187:305-320.

33. Tasi G, Palinko I, Nyerges L, Fejes P, Foerster H. Calculation of electrostatic potential maps and atomic charges for large molecules. J Chem Inf Comput Sci 1993; 33:296-299.

34. Frisch A, Nielson AB, Holder AJ, Editors. GAUSSVIEW User Manual. Pittsburgh, PA: Gaussian Inc.; 2000.

35. McQuarrie DA, Simon JD, Editors. Physical Chemistry. Sausalito, California: University Science Books; 1997.

36. Nozad AG, Meftah S, Ghasemi MH, Kiyani RA, Aghazadeh M. Investigation of intermolecular hydrogen bond interactions in crystalline L-cysteine by DFT calculations of the oxygen-17, nitrogen-14, and hydrogen-2 EFG tensors and AIM analysis. Biophys Chem 2009; 141:49-58.

37. Shayan K, Nowroozi A. Boron nitride nanotubes for delivery of 5-fluorouracil as anticancer drug: a theoretical study. Appl Surf Sci 2018; 428:500-513. 
38. Chattaraj PK, Poddar A. Molecular reactivity in the ground and excited electronic states through density-dependent local and global reactivity parameters. J Phys Chem A 1999; 103:8691-8699.

39. Prystupa DA, Anderson A, Torrie BH. Raman and infrared study of solid benzyl alcohol. J Raman Sectors 1994; 25:175-182.

40. Bader RFW, Editor. Atoms in molecules: a quantum theory. USA: Oxford University Press; 1994.

41. Bader, RFW. TT Nguyen-dang. Quantum theory of atoms in molecules-dalton revisited. Adv Quantum Chem 1998; 14:63-124.

42. Bader RFW. Principle of stationary action and the definition of a proper open system. Phys Rev B 1994; $49: 13348$. 